\title{
REGULAR SEMI-CONTINUOUS METHODS OF SUMMATION OF FOURIER SERIES
}

\author{
A. D. Nakhman ${ }^{1}$, B. P. Osilenker ${ }^{2}$ \\ Department "Engineering Mechanics and Machine Parts", \\ TSTU, Tambov, Russia (1); alextmb@mail.ru; \\ department "Applied Mathematics", Moscow State University \\ of Civil Engineering, Moscow, Russia (2)
}

Keywords: convex and piecewise convex summing sequences; Fourier series; weighted estimates of maximal operators.

Abstract: In this paper, using the semi-continuous summation methods, we build a class of means of Fourier series, that converge almost everywhere, as well as in metrics of weighted spaces $L_{v}^{p} \quad\left(v \in A_{p}, p \geq 1\right)$ and the space $C$ of continuous periodic functions. It was found that a sufficient condition for such convergence, and the equity of weighting estimates of corresponding maximal operators, is the generalized condition of B. Nagy. The results are applied to study of behavior of exponential means of Fourier series and include the cases of classical means of Cesaro, Riesz, and Abel-Poisson.

\section{Introduction}

The problem of summability of Fourier series has a long history. It occurs primarily in connection with the examples of divergent Fourier series. Linear means of such series are an effective device of approximation of periodic functions. With an appropriate choice of a summing sequence they can be used to obtain the solution of the generalized Dirichlet problem in a circle or half-plane [1]. There are also other applications.

In this paper, using the semi-continuous summation methods, we build the class of means, convergent in metrics of certain functional spaces and almost everywhere.

Let $L(Q)$ be a space of $2 \pi$-periodic functions $f$, integrable on $Q=(-\pi, \pi]$. Consider the Fourier series of function $f$

$$
s[f, x]=\sum_{k=-\infty}^{\infty} c_{k}(f) \exp (i k x),
$$

here

$$
c_{k}(f)=\frac{1}{2 \pi} \int_{-\pi}^{\pi} f(t) \exp (-i k t) d t, \quad k=0, \pm 1, \pm 2, \ldots,
$$

is the sequence of Fourier coefficients. 
In general, the problem is formulated as follows: what conditions must be imposed on the elements of an infinite sequence

$$
\Lambda=\left\{\lambda_{k}(h), h>0, k=0,1, \ldots ; \lambda_{0}(h)=1\right\}
$$

to approximate $f$ by the family of respective means

$$
U_{h}(f)=U(f, x ; \Lambda, h)=\sum_{k=-\infty}^{\infty} \lambda_{|k|}(h) c_{k}(f) \exp (i k x), h \rightarrow+0,
$$

a) at each point of continuity;

b) uniformly in $x$ for every continuous function;

c) in the metric of weighted Lebesgue spaces (see definition below);

g) almost everywhere.

There is a series of works that explore the behavior of (3) when the summing sequence (2) is defined by discrete values of parameter $h$, namely, can be written in form of a triangular matrix

$$
\Lambda=\left\{\lambda_{k}^{n} ; k=0,1, \ldots, n ; n=0,1, \ldots ; \lambda_{0}^{n}=1, \lambda_{k}^{n}=0, k>n\right\} .
$$

Thus, A. V. Efimov [2], by improving of the results of Nikol'skii [3] and B. Nadgy [4], has received the conditions on the matrix, providing the summability of Fourier series in the Lebesgue points of functions $f \in L(Q)$ and in metric of the space of continuous functions. L. I. Bausov [5] has strengthened the results of Karamata and Tomic [6] and A. V. Efimov for a case of rectangular summing matrices $\Lambda$.

\section{Weighted estimates for the maximum function of Hardy-Littlewood}

At the heart of our consideration will be weight estimates of the maximum operator

$$
U^{*}(f)=U^{*}(f, x ; \lambda)=\sup _{h>0}|U(f, x ; \lambda, h)|
$$

and the suggestions of summability of Fourier series will follow of them.

Let $L_{v}^{p}=L_{v}^{p}(Q)$ be class of measurable on $Q=(-\pi, \pi]$ and $2 \pi$-periodic functions $f$ such as

$$
\|f\|_{v, p}=\left(\int_{Q}|f(x)|^{p} v(x) d x\right)^{1 / p}<\infty, \quad p \geq 1 .
$$

Here the weight function $v=v(x) \geq 0$ is also measurable on $Q=(-\pi, \pi]$ and $2 \pi$-periodic; in the case of $v \equiv 1$ we have classical Lebesgue spaces $L^{p}=L^{p}(Q)$; $L=L^{1}(Q)$.

Denote

$$
A_{p}(v ; \Omega)=\left(\frac{1}{|\Omega|} \int_{\Omega} v(t) d t\right)\left(\frac{1}{|\Omega|} \int_{\Omega} v^{-1 /(p-1)}(t) d t\right)^{p-1}, \quad p \geq 1,
$$

where $\Omega$ is an arbitrary interval, and multiplier $\left(\int_{\Omega} v^{-1 /(p-1)}(t) d t\right)^{p-1}$ is equal $\underset{t \in \Omega}{\operatorname{esssup}} \frac{1}{v(t)}$ for $p=1$ by definition. 
We say that $A_{p}$-condition of Muckenhoupt-Rozenblum [7,8] is satisfied and apply the notation $v \in A_{p}$, if $\sup _{\Omega} A_{p}(v ; \Omega)<\infty, p \geq 1$. In present work, as well as in [8], we suppose $0 \cdot \infty=0$. Then

$$
\left(\int_{Q} v^{-1 /(p-1)}(t) d t\right)^{p-1}<\infty \text { for } v \in A_{p}(p \geq 1),
$$

since otherwise $\int_{Q} v(t) d t=0$, but this trivial case of $v \sim 0 \quad(v(x)=0$ almost everywhere), we exclude from consideration.

It is possible to consider now, that everyone $f \in L_{v}^{p}(Q)$ is a function from $L(Q)$, which corresponds to a case of $v \equiv 1, p=1$. Really

$$
\int_{Q}|f(t)| d t \leq\left(\int_{Q}|f(t)|^{p} v(t) d t\right)^{1 / p}\left(\int_{Q} v^{-1 /(p-1)}(t) d t\right)^{(p-1) / p}<\infty
$$

we have used here the Helder inequality for $p>1$ and the agreement on $\left(\int_{\Omega} v^{-1 /(p-1)}(t) d t\right)^{p-1}$ for $p=1$.

Exclude from consideration a trivial case of $v(x) \sim \infty$. Then $\int_{Q} v(x) d x<\infty$, since otherwise $A_{p}$-condition implies the relation $\left(\int_{Q} v^{-1 /(p-1)}(t) d t\right)^{p-1}=0$, so that $v \sim \infty$. Let $E$ be a set which is measurable by Lebesque. Introduce now the following measure of $E: \mu\{E\}=\int_{E} v(x) d x$.

For each $f \in L$ the maximal function of Hardy-Littlewood

$$
f^{*}=f^{*}(x)=\sup _{\eta>0} \frac{1}{\eta} \int_{x-\eta}^{x+\eta}|f(t)| d t
$$

is defined [9, v. 1, p. 60-61; p. 401, 442, 443]. By the results of [8] the estimate of "strong type"

$$
\left\|f^{*}\right\|_{v, p} \leq C_{v, p}\|f\|_{v, p}
$$

is equivalent to the condition $v \in A_{p}, p>1$. In addition, the estimate of "weak type"

$$
\mu\left\{x \in Q \mid f^{*}(x)>\varsigma>0\right\} \leq C_{v, p}\left(\frac{\|f\|_{v, p}}{\varsigma}\right)^{p}
$$

is equivalent to the condition $v \in A_{p}, \quad p \geq 1$.

Here and below, $C$ will represent a constant (though not necessarily one such constant), which may depend only on indicated indexes.

\section{Estimates of the operators generated by semi-continuous methods of summation}

Denote $\Delta \lambda_{k}(h)=\lambda_{k}(h)-\lambda_{k+1}(h), \Delta^{2} \lambda_{k}(h)=\Delta\left(\Delta \lambda_{k}(h)\right), k=0,1, \ldots$.

Theorem 2.1. Let the members of sequence (2) at each $h>0$ satisfy the condition

$$
\lambda_{k}(h)=O\left(\frac{1}{\ln k}\right), k \rightarrow \infty
$$


Suppose that $m \geq 0$ is chosen arbitrarily ( $m$ may depend on $h$ ) and $\rho=[m / 2]$. Then for all $h>0$ and almost all $x$ the estimate

$$
U(f, x ; \lambda, h) \leq C f^{*}(x) \sum(h, \Lambda, m)
$$

holds. Here

$$
\begin{gathered}
\sum(h, \Lambda, m)=\max _{k=0,1, \ldots}\left|\lambda_{k}(h)\right|+ \\
+\sum_{k=0}^{\rho}(k+1)\left|\Delta^{2} \lambda_{k}(h)\right|+\sum_{k=2 m}^{\infty}(k+1)\left|\Delta^{2} \lambda_{k}(h)\right|+\sum_{k=\rho+1}^{2 m-1}(|m-k|+1) \ln \frac{2(m+k+1)}{|m-k|+1}\left|\Delta^{2} \lambda_{k}(h)\right| .
\end{gathered}
$$

Proof. We assume that the sum on the right side (8) is finite (otherwise the theorem is trivial). future:

1. First of all, we note a number of relations that will be needed here and in the

$$
\begin{gathered}
(n+1)\left|\Delta \lambda_{n}(h)\right| \leq \sum_{k=n}^{\infty}(k+1)\left|\Delta^{2} \lambda_{k}(h)\right|, \quad n=1,2, \ldots ; \\
\sum_{k=0}^{\infty}\left|\Delta \lambda_{k}(h)\right| \leq \sum_{k=0}^{\infty}(k+1)\left|\Delta^{2} \lambda_{k}(h)\right| \\
\lambda_{k}(h)=\sum_{s=k}^{\infty} \Delta \lambda_{k}(h), \quad k=0,1, \ldots ; \\
(\rho+1) \Delta \lambda_{\rho+1}(h)=\lambda_{0}(h)-\lambda_{\rho+1}(h)+\sum_{k=0}^{\rho}(k+1) \Delta^{2} \lambda_{k}(h) .
\end{gathered}
$$

Methods of proof of inequalities (9) - (12) are standard [2,5]. We obtain the relation (9). According to (7) $\lambda_{k}(h) \rightarrow 0(k \rightarrow \infty)$ at all $h>0$, and therefore, $\lim _{k \rightarrow \infty} \Delta \lambda_{k}(h)=0$. Then

$$
\Delta \lambda_{n}(h)=\sum_{k=n}^{\infty} \Delta^{2} \lambda_{k}(h)
$$

Hence,

$$
(n+1)\left|\Delta \lambda_{n}(h)\right|=(n+1)\left|\sum_{k=n}^{\infty} \Delta^{2} \lambda_{k}(h)\right| \leq \sum_{k=n}^{\infty}(n+1)\left|\Delta^{2} \lambda_{k}(h)\right| \leq \sum_{k=n}^{\infty}(k+1)\left|\Delta^{2} \lambda_{k}(h)\right|
$$

so that, in particular

$$
(n+1)\left|\Delta \lambda_{n}(h)\right| \rightarrow 0, \quad n \rightarrow \infty .
$$

The relation (11) obviously follows from (13), equality (12) is obtained by applying to the sum recorded in right part, the Abel transform.

To prove (10), we obtain by Abel transform,

$$
\begin{gathered}
\sum_{k=0}^{\infty}\left|\Delta \lambda_{k}(h)\right|=\sum_{k=0}^{\infty}((k+1)-k)\left|\sum_{j=k}^{\infty} \Delta^{2} \lambda_{k}(h)\right|= \\
=\lim _{N \rightarrow \infty}\left((N+1)\left|\Delta \lambda_{N}(h)\right|+\sum_{k=0}^{N-1}(k+1)\left(\left|\sum_{j=k}^{\infty} \Delta^{2} \lambda_{k}(h)\right|-\left|\sum_{j=k+1}^{\infty} \Delta^{2} \lambda_{k}(h)\right|\right) .\right.
\end{gathered}
$$


According to (13), the right-hand side of this relation does not exceed

$$
\sum_{k=0}^{\infty}(k+1)\left|\sum_{j=k}^{\infty} \Delta^{2} \lambda_{k}(h)-\sum_{j=k+1}^{\infty} \Delta^{2} \lambda_{k}(h)\right|,
$$

which implies the estimate (10).

2. Consider the kernels of Dirichlet, Fejer ([9], vol. 1, pp. 86, 148) and Vale Poussin [2], respectively:

$$
\begin{gathered}
D_{k}(t)=\frac{1}{2}+\sum_{v=1}^{k} \cos v t=\frac{\sin \left(k+\frac{1}{2}\right) t}{2 \sin \frac{1}{2} t} ; \\
F_{k}(t)=\frac{1}{k+1} \sum_{v=0}^{k} D_{v}(t)=\frac{\sin ^{2} \frac{k+1}{2} t}{2(k+1) \sin ^{2} \frac{1}{2} t}, \quad F_{-1}(t) \equiv 0 ; \\
V_{m, k}(t)=\frac{\sin \frac{m-k+1}{2} t \cdot \sin \frac{m+k+1}{2} t}{2(m-k+1) \sin ^{2} \frac{t}{2}}, \quad V_{m, m+1}(t)=\frac{t \sin (m+1) t}{4 \sin ^{2} \frac{t}{2}} .
\end{gathered}
$$

It is easy to verify that for all $k=0,1, \ldots, m=0,1, \ldots$

$$
\begin{gathered}
D_{k}(t)=(k+1) F_{k}(t)-k F_{k-1}(t) ; \\
D_{k}(t)=(m-k+1) V_{m, k}(t)-(m-k) V_{m, k+1}(t),
\end{gathered}
$$

3. Next, move on to the integral form (3), using the representation (1) of Fourier coefficients and Abel transform. We obtain

$$
\begin{gathered}
U(f, x ; \lambda, h)=\lim _{N \rightarrow+\infty} \frac{1}{\pi} \int_{-\pi}^{\pi} f(t)\left\{\frac{1}{2}+\sum_{k=1}^{N} \lambda_{k}(h) \cos k(x-t)\right\} d t= \\
\lim _{N \rightarrow+\infty} \frac{1}{\pi} \int_{-\pi}^{\pi} f(x+t)\left\{\frac{1}{2}+\sum_{k=1}^{N} \lambda_{k}(h)\left(D_{k}(t)-D_{k-1}(t)\right)\right\} d t= \\
=\frac{1}{\pi} \lim _{N \rightarrow+\infty}\left\{\lambda_{N}(h) \int_{-\pi}^{\pi} f(x+t) D_{N}(t) d t+\int_{-\pi}^{\pi} f(x+t) \sum_{k=0}^{N-1} \Delta \lambda_{k}(h) D_{k}(t) d t\right\} .
\end{gathered}
$$

Note that for each $f \in L(Q)$ almost everywhere (ie, at each Lebesgue point) the relation $[9$, vol. 1, p. 113]

$$
\left|\int_{-\pi}^{\pi} f(x+t) D_{N}(t) d t\right|=o(\ln N), \quad N \rightarrow \infty
$$

holds. So, for almost all $x$

$$
U(f, x ; \lambda, h)=\frac{1}{\pi} \sum_{k=0}^{\infty} \int_{-\pi}^{\pi} f(x+t) \Delta \lambda_{k}(h) D_{k}(t) d t=
$$




$$
\begin{gathered}
=\frac{1}{\pi} \int_{-\pi}^{\pi} f(x+t)\left\{\sum_{k=0}^{\rho} \Delta \lambda_{k}(h)\left((k+1) F_{k}(t)-k F_{k-1}(t)\right)\right\} d t+ \\
+\frac{1}{\pi} \int_{-\pi}^{\pi} f(x+t)\left\{\sum_{k=\rho+1}^{2 m} \Delta \lambda_{k}(h)\left((m-k+1) V_{m, k}(t)-(m-k) V_{m, k+1}(t)\right)\right\} d t+ \\
+\frac{1}{\pi} \lim _{N \rightarrow \infty} \int_{-\pi}^{\pi} f(x+t)\left\{\sum_{k=2 m+1}^{N} \Delta \lambda_{k}(h)\left((k+1) F_{k}(t)-k F_{k-1}(t)\right)\right\} d t .
\end{gathered}
$$

Using the equations (15), (16) and the Abel transform, we have from (17)

$$
\begin{gathered}
U(f, x ; \lambda, h)= \\
=\frac{1}{\pi} \int_{-\pi}^{\pi} f(x+t)\left\{\Delta \lambda_{\rho}(h)(\rho+1) F_{\rho}(t)+\sum_{k=0}^{\rho-1} \Delta^{2} \lambda_{k}(h)(k+1) F_{k}(t)\right\} d t+ \\
+\frac{1}{\pi} \int_{-\pi}^{\pi} f(x+t)\left\{\Delta \lambda_{2 m}(h) \cdot m V_{m, 2 m+1}(t)+\Delta \lambda_{\rho+1}(h)(m-\rho) V_{m, \rho+1}(t)-\right. \\
+\frac{1}{\pi} \lim _{N \rightarrow \infty} \int_{-\pi}^{\pi} f(x+t)\left\{\Delta \lambda_{N}^{2 m-1} \Delta^{2} \lambda_{k}(h)(m-k)(N+1) F_{N}(t)-\Delta \lambda_{2 m+1}(h) \cdot(2 m+1) \cdot F_{2 m}(t)+\right. \\
\left.+\sum_{k=2 m+1}^{N} \Delta^{2} \lambda_{k}(h)(k+1) F_{k}(t)\right\} d t .
\end{gathered}
$$

4. Next, set the following estimates for the integrals contained in the right-hand side of (7):

$$
\begin{gathered}
\int_{-\pi}^{\pi}|f(x+t)| F_{k}(t) d t \leq C f^{*}(x), \quad k=0,1, \ldots ; \\
\int_{-\pi}^{\pi}|f(x+t)|\left|V_{m, k}(t)\right| d t \leq C \ln \frac{2(m+k+1)}{|m-k|+1} f^{*}(x), \quad k=0,1, \ldots ; m=0,1, \ldots .
\end{gathered}
$$

Note that (20) is of independent interest.

We prove (20); the estimate (19) will then follow from equality $F_{k}(t)=V_{k, 0}(t)$, $k=0,1, \ldots$. From definition (14) easily follow the inequalities

$$
\begin{gathered}
\left|V_{m, k}(t)\right| \leq C(m+k+1), \quad 0 \leq t \leq \pi, \quad k=0,1, \ldots ; \quad m=0,1, \ldots ; \\
\left|V_{m, k}(t)\right| \leq C \frac{1}{|t|}, \quad 0<|t| \leq \pi, \quad k=0,1, \ldots ; \quad m=0,1, \ldots ; \\
\left|V_{m, k}(t)\right| \leq C \frac{1}{(|m-k|+1) t^{2}}, \quad 0<|t| \leq \pi, \quad k=0,1, \ldots ; \quad m=0,1, \ldots .
\end{gathered}
$$


Choose natural numbers $S_{1}=S(k, m)$ and $S_{2}=S(k, m)$, so that

$$
\frac{2^{S_{1}-1}}{m+k+1} \leq \frac{1}{|m-k|+1}<\frac{2^{S_{1}}}{m+k+1}, \quad \frac{2^{S_{2}-1}}{|m-k|+1} \leq \pi<\frac{2^{S_{2}}}{|m-k|+1} .
$$

By (21) - (23), we have

$$
\begin{gathered}
\left|\int_{-\pi}^{\pi} f(x+t) V_{m, k}(t) d t\right| \leq C(m+k+1) \quad \int_{|t| \leq \frac{1}{m+k+1}}^{\int}|f(x+t)| d t+ \\
+C \sum_{j=1}^{S_{1}} \frac{m+k+1}{2^{j-1}} \int_{\frac{2^{j-1}}{m+k+1} \leq|t| \leq \frac{2^{j}}{m+k+1}}|f(x+t)| d t+C \sum_{j=1}^{S_{2}} \frac{1}{2^{j-1}}\left(\begin{array}{c}
\frac{|m-k|+1}{2^{j-1}} \\
\frac{2^{j-1}}{|m-k|+1} \leq|t| \leq \frac{2^{j}}{|m-k|+1}
\end{array}\right) \leq \\
\leq C\left(1+S_{1}\right) f^{*}(x) \leq C \ln \frac{2(m+k+1)}{|m-k|+1} f^{*}(x) ;
\end{gathered}
$$

on receipt these relations it was used obvious estimate of the form

$$
\begin{aligned}
& \frac{q}{2^{j-1}} \quad \int|f(x+t)| d t \leq 2 \frac{q}{2^{j}} \quad \int|f(x+t)| d t=2 \frac{q}{2^{j}} \quad \int|f(t)| d t \leq C f^{*}(x), \\
& \frac{2^{j-1}}{q} \leq|t| \leq \frac{2^{j}}{q} \quad 2^{j} \quad x-|t| \leq \frac{2^{j}}{q} \quad 2^{j} \quad \frac{2^{j}}{q} \leq t \leq x+\frac{2^{j}}{q}
\end{aligned}
$$

wherein $q=m+k+1$ или $q=|m-k|+1$.

Thus, the assertion (20) is established.

5. To complete the proof of (8), we apply to (18) the estimates (19) and (20). Taking into account that the ratio $\frac{m+\rho+2}{m-\rho+1}$ (arising under the logarithm) lies between two positive constants, we have

$$
\begin{gathered}
|U(f, x ; \lambda, h)| \leq \\
\leq C f^{*}(x)\left\{\left|\Delta \lambda_{\rho}(h)\right|(\rho+1)+\sum_{k=0}^{\rho-1}\left|\Delta^{2} \lambda_{k}(h)\right|(k+1)+\right. \\
+\left|\Delta \lambda_{2 m}(h)\right| m+\left|\Delta \lambda_{\rho+1}(h)\right|(m-\rho)+\sum_{k=\rho+1}^{2 m-1}\left|\Delta^{2} \lambda_{k}(h)\right|(|m-k|+1) \ln \frac{2(m+k+1)}{|m-k|+1}+ \\
\left.+\lim _{N \rightarrow \infty}\left|\Delta \lambda_{N}(h)\right|(N+1)+\left|\Delta \lambda_{2 m+1}(h)\right|(2 m+1)+\lim _{N \rightarrow \infty} \sum_{k=2 m+1}^{N}\left|\Delta^{2} \lambda_{k}(h)\right|(k+1)\right\} .
\end{gathered}
$$

Using (9) for $n=2 m, n=2 m+1$, (12) and (13), we obtain from (24) the statement (8). The theorem is completely proved.

Remark 1. In the case of $m=0$ we obtain at all $h>0$ and at almost all $x$ from (8) and (10) - (11)

$$
U(f, x ; \lambda, h) \leq C f^{*}(x) \sum_{k=0}^{\infty}(k+1)\left|\Delta^{2} \lambda_{k}(h)\right|
$$


The relation (25) holds since the sum

$$
\sum_{k=\rho+1}^{2 m-1}(|m-k|+1) \ln \frac{2(m+k+1)}{|m-k|+1}\left|\Delta^{2} \lambda_{k}(h)\right| .
$$

in (8) is "empty".

Remark 2. If the parameter $h$ ranges the discrete values $h=\frac{1}{m+1}, m=0,1, \ldots$, so that $\lambda_{k}(h)=\lambda_{k}^{m}$ in (2) and $\lambda_{k}^{m}=0$ if $k=0,1, \ldots$, then in the right side of (8) we obtain a sum of B. Nagy [4]:

$$
\begin{aligned}
U(f, x ; \lambda, h) \leq C f^{*}(x) \sup _{m=0,1, \ldots}\left\{\max _{k=0,1, \ldots, m}\left|\lambda_{k}^{m}\right|+\sum_{k=0}^{\rho}\left|\Delta^{2} \lambda_{k}^{m}\right|(k+1)+\right. \\
\left.+\sum_{k=\rho+1}^{m}\left|\Delta^{2} \lambda_{k}^{m}\right|(m-k+1) \ln \frac{2(m+k+1)}{m-k+1}\right\} .
\end{aligned}
$$

\section{Weighted estimates for the maximal operator}

Theorem 3.1. Suppose there is a constant $C=C_{\lambda}$ such that the sequence (2) for all $h>0$ satisfies the conditions (7) and

$$
\sum(h, \Lambda, m) \leq C_{\lambda} .
$$

If $v \in A_{p}$, then the estimates

$$
\begin{gathered}
\left\|U_{*}(f)\right\|_{v, p} \leq C_{\lambda, p}\|f\|_{v, p}, \quad p>1 ; \\
\mu\left\{x \in Q \mid U_{*}(f, x ; \lambda)>\varsigma>0\right\} \leq C_{\lambda, p}\left(\frac{\|f\|_{v, p}}{\varsigma}\right)^{p}, p \geq 1
\end{gathered}
$$

are valid.

The result is an immediate consequence of (4), (8), (26) and the estimates of strong and weak type (5), (6), respectively.

\section{Summability in metric of the spaces $C, L_{v}^{p}$ and almost everywhere}

Theorem 4.1 Let the sequence (2) satisfies the conditions (7), (26) and

$$
\lim _{h \rightarrow 0} \lambda_{k}(h)=1 ; k=0,1, \ldots
$$

Then the relation

$$
U_{h}(f)=f
$$

holds

a) in metric of space $C=C(Q)$ of $2 \pi$-periodic functions continuous on $Q$;

b) in metrics of each of the spaces $L_{v}^{p}, \quad p \geq 1$, if $v \in A_{p}$;

c) almost everywhere for each $f \in L_{v}^{p}, p \geq 1$, if $v \in A_{p}$. 
Proof. We begin by considering of functions of the space $C=C(Q)$. Note that the representation (18) is valid now at every point $x$ (any $x$ is Lebesgue point); denote the right-hand side (18) by $U^{+}(f, x ; h, \Lambda)$. The family of norms of operators $U_{h}(f)$, acting from $C$ to $C$, is uniformly bounded:

$$
\left\|U_{h}(f)\right\|=\max _{\|f\| \leq 1} U^{+}(f, x ; h, \Lambda) \leq C \sum(h, \Lambda, m) .
$$

Further, according to (27), we have a uniform (at $h>0$ ) boundedness of the family of norms of operators, acting from $L_{v}^{p}$ in $L_{v}^{p}$, if $v \in A_{p}, p>1$. In the case of $p=1$ we restrict ourselves by calculations for $m=0$, because the calculations in general case are similar but more cumbersome. We get from (24) by a change of variables $\tau=x+t$ :

$$
\begin{gathered}
\left\|U_{h}(f)\right\|_{v, 1} \leq \int_{-\pi}^{\pi}\left|\sum_{k=0}^{\infty}(k+1) \Delta^{2} \lambda_{k}(h) \int_{-\pi}^{\pi} f(x+t) F_{k}(t) d t\right| v(x) d x \leq \\
\leq \int_{-\pi}^{\pi} \sum_{k=0}^{\infty}(k+1)\left|\Delta^{2} \lambda_{k}(h)\right|\left(\int_{-\pi}^{\pi}|f(x+t)| F_{k}(t) d t\right) v(x) d x= \\
=\int_{-\pi}^{\pi} \lim _{N \rightarrow \infty} \sum_{k=0}^{N}(k+1)\left|\Delta^{2} \lambda_{k}(h)\right|\left(\int_{-\pi}^{\pi}|f(x+t)| F_{k}(t) d t\right) v(x) d x= \\
=\int_{-\pi}^{\pi}|f(\tau)| d \tau \int_{-\pi}^{\pi} v(x) \sum_{k=0}^{\infty}(k+1)\left|\Delta^{2} \lambda_{k}(h)\right| F_{k}(x-\tau) d x \leq \\
\leq C\left(\int_{-\pi}^{\pi}|f(\tau)| v^{*}(\tau) d \tau\right) \sum_{k=0}^{\infty}(k+1)\left|\Delta^{2} \lambda_{k}(h)\right| .
\end{gathered}
$$

As is well known [8], the condition $v \in A_{1}$ is equivalent to

$$
v^{*}(\tau) \leq C v(\tau)
$$

so that (32), (33) imply the estimate

$$
\left\|U_{h}(f)\right\|_{v, 1} \leq C\|f\|_{v, 1} \sum_{k=0}^{\infty}(k+1)\left|\Delta^{2} \lambda_{k}(h)\right| .
$$

Thus, according to (31) and (27), (34) the family of norms of operators $U_{h}(f)$ is bounded from $C$ in $C$ and from $L_{v}^{p}$ in $L_{v}^{p}$, if $v \in A_{p}, p \geq 1$. Now, by virtue of the Banach-Steinhaus theorem, the convergence (30) in metric of the appropriate space follows from (29), which completes the proof of claims a) and b) of Theorem.

The assertion c) follows by the standard way [9, vol. 2, pp. $464-465]$ from the estimate of weak type (28) and the results of a) and b).

Theorem 4.1 is proved.

Remark 1. It can be shown that the conditions (7), (26), (29), provide a regularity of semi-continuous methods of summation (2) [10, p. 79]. In the case of $m=0$ this assertion follows from (10).

Remark 2. Let the summation methods defined by rectangular matrices $\Lambda=\left\{\lambda_{k}^{n} ; k=0,1, \ldots ; n=0,1, \ldots ; \lambda_{0}^{n}=1\right\}$ 
satisfy the condition

$$
\sum_{k=0}^{[m / 2]}(k+1)\left|\Delta^{2} \lambda_{k}^{n}\right|+\sum_{k=[m / 2]+1}^{\infty}(|m-k-1|)\left|\Delta^{2} \lambda_{k}^{n}\right| \leq C_{\lambda}
$$

for some integer $m>0$. In [5] for this case were found the necessary and sufficient conditions of $\Lambda$-summability of Fourier series in metric of the space $C$ and in every point of Lebesgue. It is easy to verify that condition (35) is equivalent to the following:

$$
\sum_{k=0}^{[m / 2]}(k+1)\left|\Delta^{2} \lambda_{k}^{n}\right|+\sum_{k=[m / 2]+1}^{2 m-2}(|m-k-1|)\left|\Delta^{2} \lambda_{k}^{n}\right|+\sum_{k=2 m-1}^{\infty}(k+1)\left|\Delta^{2} \lambda_{k}^{n}\right| \leq C_{\lambda},
$$

so that the terms of the second sum in (35) for values of $k$, isolated on the selected $m$, behave like $(k+1)\left|\Delta^{2} \lambda_{k}^{n}\right|$.

\section{Concave and convex piecewise summation methods}

The sequence (2) is called convex (concave), if $\Delta^{2} \lambda_{k}(h) \geq 0\left(\Delta^{2} \lambda_{k}(h) \leq 0\right)$ at all $k=0,1, \ldots$. The sequence (2) is called a piecewise-convex if the second finite differences $\Delta^{2} \lambda_{k}(h)$ have a finite number of sign changes (the value $k$, at which the sign changes, occurs may depend on $h$ ).

Theorem 5.1. If the convex (concave) sequence (2) satisfies (7), and $v \in A_{p}$, then (at the appropriate values of $p$ ) the estimates (27), (28) hold.

If the condition (29) are carried also, the statements on the convergence a), b), c) of Theorem 4.1 are valid.

Theorem 5.2. Let piecewise convex sequence (2) satisfies (7) and there is a constant $C_{\Lambda}$ such that for all $h>0, k=1,2, \ldots$

$$
\left|\lambda_{k}(h)\right|+k\left|\Delta \lambda_{k}(h)\right| \leq C_{\lambda} .
$$

If $v \in A_{p}$, then (with appropriate values of $p$ ) the estimates (27), (28) hold.

If the condition (29) are carried also, the statements on the convergence a), b), c) of Theorem 4.1 are valid.

Proof, as above, will be based on the estimate $U_{*}(f, x ; \lambda) \leq C_{\lambda} f^{*}(x)$. In turn, its obtaining is based on the relations (7), (13) and (26). The relation (13) holds for every convex sequence $[9$, vol. 1, p. 156] and, therefore, (13) remains valid for any piecewiseconvex sequence (it is clear that any piecewise-convex sequence (2) becomes a concave or convex for sufficiently large values $k$ ).

Now it is enough to verify the implementability of the condition (26); choose $m=0$. Consider the case of piecewise-convex sequence $\Lambda$. Then $\Delta^{2} \lambda_{k}(h)$ remain its sign for $l \leq k \leq n$, where $l$ and $n$ are some natural numbers. Using the Abel transformation, we obtain

$$
\sum_{k=l}^{n}(k+1) \Delta^{2} \lambda_{k}(h)=\lambda_{l+1}(h)-\lambda_{n+1}(h)+(l+1) \Delta \lambda_{l}(h)-(n+1) \Delta \lambda_{n+1}(h) .
$$

Hence, $\sum_{k=0}^{\infty}(k+1)\left|\Delta^{2} \lambda_{k}(h)\right|$ is equal to finite number of sums, each of which looks like (37); therefore, according to (36), the sum (37) is bounded above by some constant $C_{\lambda}$. In the case of a convex sequence, the sum (37) for $l=0$ takes form

$$
\lambda_{1}(h)+\Delta \lambda_{0}(h)=\lambda_{0}(h)=1 .
$$

So, in the conditions of Theorems 5.1, 5.2, the estimate (26) for $m=0$ is satisfied, and this completes the proof. 


\section{Exponential summation methods}

Consider now the semi-continuous summation methods, appropriate to the occasion

$$
\lambda_{0}(h)=1, \quad \lambda_{k}(h)=\left.\lambda(x, h)\right|_{x=k}, \quad k=1,2, \ldots, \lambda(x, h)=\exp (-h \varphi(x)),
$$

$\varphi(x) \in C^{2}(0,+\infty)$ and $\varphi(x)$ increases to $+\infty$.

Note that for $\lambda(x, h)=\exp (-h x)$ we have the Abel-Poisson means [9, vol. 1 , p. $160-165]$.

By virtue of Lagrange's theorem, we obtain

$$
\begin{gathered}
\Delta \lambda_{k}(h)=h \varphi^{\prime}\left(k+\theta_{1}\right) \exp \left(-h \varphi\left(k+\theta_{1}\right)\right) ; \\
\Delta \lambda_{k+1}(h)=h \varphi^{\prime}\left(k+1+\theta_{2}\right) \exp \left(-h \varphi\left(k+\theta_{2}\right)\right) ; \\
\Delta^{2} \lambda_{k}(h)=\left(1+\theta_{2}-\theta_{1}\right) h\left(h\left(\varphi^{\prime}(k+\theta)\right)^{2}-\varphi^{\prime \prime}(k+\theta)\right) \exp (-h \varphi(k+\theta)),
\end{gathered}
$$

here $\theta=\theta_{3}\left(1+\theta_{2}-\theta_{1}\right), 0<\theta_{1}, \theta_{2}, \theta_{3}<1$, so that $0<\theta<2$. Put

$$
\psi(x)=h\left(\varphi^{\prime}(x)\right)^{2}-\varphi^{\prime \prime}(x), \quad x>0 .
$$

Corollary 6.1. If a function, defined in (38), satisfies the condition

$$
\exp (-h \varphi(x))=O\left(\ln ^{-1} x\right), \quad x \rightarrow+\infty, \quad h>0,
$$

and $\varphi^{\prime \prime}(x) \leq 0, x \in(0,+\infty)$, then the assertion of Theorem 5.1 are valid.

Indeed, under the condition of (42), the relation (7) hold and, according to (40), the sequence (2) is convex.

Corollary 6.2. Let $\varphi(x)$, defined in (38), satisfies (42),

$$
h x \varphi^{\prime}(x) \exp (-h \varphi(x)) \leq C_{\varphi}
$$

for some constant $C_{\varphi}$, and $\psi(x), x \in(0,+\infty)$, defined in (41), has a finite number of sign changes. Then the assertions of Theorem 5.1 are valid.

Indeed, by (42) and (39), (43) the conditions (7) and (36) are implemented respectively. In this case, according to (40), the sequence (2) will be a piecewise convex.

\section{Examples}

7.1. Consider the following two cases of (38):

$$
\varphi(x)=\ln ^{\alpha}(x+1), \quad x>0, \quad \alpha>0
$$

and

$$
\varphi(x)=x^{\alpha}, \quad x>0, \quad \alpha>0 .
$$

For each of the functions (44), as was shown in [11], are applicable the conditions of the corollaries 6.1 and 6.2 at $0<\alpha \leq 1$ and $\alpha>1$, respectively. Consequently, for the respective means (3) are valid the estimates of form (27), (28) and the assertions of convergence a), b), c) of Theorem 4.1.

In particular (see (45), $\alpha=1$ ) the classical results on the convergence of AbelPoisson means $[9$, vol. 1, p.166; 7; 8] are valid.

7.2. The summation method (38), defined by the function

$$
\varphi(x)=P_{n}(x), \quad x>0,
$$

where $P_{n}(x)=a_{n} x^{n}+a_{n-1} x^{n-1}+\ldots+a_{0}$ is some polynomial $\left(a_{n}>0, n=1,2, \ldots\right)$, satisfies the conditions of Corollary 6.2 [11]. So the estimates of the form (27), (28) and the assertions of convergence a), b), c) of Theorem 4.1 hold. 
7.3. Cesaro-Abel means $(C, \alpha), \alpha>0$ (see [9], vol. 1, p.131) are defined by the elements of triangular matrix

$$
\Lambda=\left\{\lambda_{k}^{m}=\frac{A_{m-k}^{\alpha}}{A_{m}^{\alpha}} ; k=0,1, \ldots, m ; m=0,1, \ldots ; \lambda_{k}^{m}=0, k>m\right\},
$$

where $A_{m}^{\alpha}=\frac{(\alpha+1) \cdot \ldots \cdot(\alpha+m)}{m !}$. Summation method (46) satisfies B. Nagy conditions [4], hence for the corresponding means the assertions of Theorems 3.1 and 4.1 are valid.

7.4. The means of Riesz [10, p. 89] are determined by a sequence

$$
\lambda_{k}(h)=(1-k h)^{\alpha}, k=0,1, \ldots,\left[\frac{1}{h}\right] ; \lambda_{k}(h)=0 \text { for } k>\left[\frac{1}{h}\right] ; 0<h \leq 1, \alpha>0,
$$

Applying the theorem of Lagrange twice, we have

and

$$
\Delta \lambda_{k}(h)=\alpha(\alpha-1) h\left(1-\left(k+\theta_{1}\right) h\right)^{\alpha-2}, 0<\theta_{1}<1 ; 0 \leq k \leq\left[\frac{1}{h}\right]-1
$$

$$
\Delta^{2} \lambda_{k}(h)=\alpha(\alpha-1) h^{2}(1-(k+\theta) h)^{\alpha-2}, \quad 0<\theta<2 ; \quad 0 \leq k \leq\left[\frac{1}{h}\right]-2 .
$$

By (48) the sequence (47) has a certain character of convexity. Noticing that the logarithmic function grows more slowly, than power function with any positive exponent, we have for all $\rho+1 \leq k \leq m$

$$
\begin{gathered}
(|m-k|+1) \ln \frac{2(m+k+1)}{|m-k|+1} \leq(m-k+1) \ln \frac{2(2 m+1)}{m-k+1} \leq C m^{\gamma}(m-k)^{1-\gamma} \leq \\
\leq C(k+1)^{\gamma}(1+k)^{1-\gamma}=C(k+1) .
\end{gathered}
$$

We choose $m=\left[\frac{1}{h}\right], \gamma \leq \alpha$ and use the assessment $\left(\frac{1}{h}-1\right) h \leq m h \leq 1$. By virtue of (47) and (37) in which $l=0, n=m-2$, the sum $\sum(h, \Lambda, m)$ in (8) does not exceed

$$
\begin{gathered}
C\left\{\sum_{k=0}^{m-2}(k+1)\left|\Delta^{2} \lambda_{k}(h)\right|+2 \ln 2 m \cdot\left|\Delta^{2} \lambda_{m-1}(h)\right|+\ln 2(2 m+1) \cdot\left|\Delta^{2} \lambda_{m}(h)\right|\right\} \leq \\
\leq C\left\{\sum_{k=0}^{m-2}(k+1)\left|\Delta^{2} \lambda_{k}(h)\right|+C m^{\gamma}\left((1-(m-1) h)^{\alpha}+(1-m h)^{\alpha}\right)\right\} \leq C_{\alpha} .
\end{gathered}
$$

According to (49), the condition (26) will be satisfied. Since the condition (7) is also satisfied, then for the corresponding means the assertions of Theorems 3.1 and 4.1 are valid.

\section{References}

1. Nahman A.D., Osilenker B.P. [Exponential Means of Fourier Series and their Application to the Decision of Generalized Dirichlet Problem], Mezhdunarodnyj zhurnal jeksperimental'nogo obrazovanija [International Journal of Experimental Education], 2014, no. 3-2, pp. 75-80. (In Russ., abstract in Eng.)

2. Efimov A.V. [On Linear Methods of Summation of Fourier Series], Izvestiya Akademii Nauk SSSR. Otdelenie matematicheskikh $i$ estestvennykh nauk. Seriya Matematicheskaya [Izvestiya of the USSR Academy of Sciences. Branch of Mathematical and Natural Sciences. Mathematical Series], 1960, no. 24, pp. 743 - 756. (In Russ.) 
3. Nikol'skij C.M. [On Linear Methods of Summation of Fourier Series], Izvestiya Akademii Nauk SSSR. Otdelenie matematicheskikh i estestvennykh nauk. Seriya Matematicheskaya [Izvestiya of the USSR Academy of Sciences. Branch of Mathematical and Natural Sciences. Mathematical Series],1948, no. 12, pp. 259-278. (In Russ.)

4. Nagy B.Sz. Methodes de sommation des series de Fourier, Acta Sci. Math. Szeged, XII., pars. B, 1950, pp. 204-210.

5. Bausov L.I. [On Linear Methods of Summation of Fourier Series], Matematicheskii sbornik [Mathematical collection], 1965, vol. 68(110), no. 3, pp. 313-327. (In Russ.)

6. Кагаmata J., Tomic M. Sur la sommation des series de Fourier des functions continue, Publ. Inst. Math. Acad. Serbe scL.,1955, no. 8, pp.123-138.

7. Rozenblum M. Summability of Fourier series in $L^{p}(d \mu)$, Trans. Amer. Math. Soc., 1962, vol. 105, pp. 32-42.

8. Muckenhoupt B. Weighted Norm Inequalities for the Hardy Maximal Function, Trans. Amer. Math. Soc.,1972, vol. 165, pp. 207-226.

9. Zygmund A. Trigonometric series, Cambridge University Press, 1959.

10. Cooke R.G. Infinite Matrices and Sequence Spaces, London : Macmillan, 1950.

11. Nakhman A.D., Osilenker B.P. Exponential methods of Summation of the Fourier Series, Transactions of the Tambov State Technical University, 2014, vol. 20, no. 1, pp. 101-109.

\title{
Регулярные полунепрерывные методы суммирования рядов Фурье
}

\author{
А. Д. Нахман ${ }^{1}$, Б. П. Осиленкер ${ }^{2}$ \\ Кафедра «Техническая механика и детали машин», \\ ФГБОУ ВО «ТГТУ», г. Тамбов, Россия (1); alextmb@mail.ru; \\ кафедра «Прикладная математика», ФГБОУ ВО «Наџиональный \\ исследовательский Московский государственный \\ строительный университет», г. Москва, Россия (2)
}

Ключевые слова: весовые оценки максимальных операторов; выпуклые и кусочно-выпуклые суммирующие последовательности; ряды Фурье.

Аннотация: Используя полунепрерывные методы суммирования, строится класс средних рядов Фурье, сходящихся почти всюду, а также в метриках весовых пространств $L_{v}^{p} \quad\left(v \in A_{p}, p \geq 1\right)$ и пространства $C$ непрерывных периодических функций. Установлено, что достаточным условием такой сходимости и справедливости $L_{v}^{p}$-весовых оценок соответствующих максимальных операторов является обобщенное условие Б. Надя. Результаты приложены к исследованию поведения экспоненциальных средних рядов Фурье и включают в себя случаи классических средних Чезаро, Рисса и Абеля-Пуассона.

\section{Список литературы}

1. Нахман, А. Д. Экспоненциальные средние рядов Фурье и их приложение к решению обобщенной задачи Дирихле / А. Д. Нахман, Б. П. Осиленкер // Междунар. журн. эксперимент. образования. - 2014. - № 3-2. - С. 75 - 80.

2. Ефимов, А. В. О линейных методах суммирования рядов Фурье / А. В. Ефимов // Изв. Акад. наук СССР. Отделение мат. и естеств. наук. Сер. мат. 1960. - № 24. - С. 743 - 756.

3. Никольский, С. М. О линейных методах суммирования рядов Фурье / С. М. Никольский // Изв. Акад. наук СССР. Отд-ние мат. и естеств. наук. Сер. мат. 1948. - № 12. - С. 259 - 278. 
4. Nagy, B. Sz. Methodes de sommation des series de Fourier / B. Sz. Nagy // Acta Sci. Math. Szeged, XII, pars. B. - 1950. - P. $204-210$.

5. Баусов, Л. И. О линейных методах суммирования рядов Фурье / Л. И. Баусов // Мат. сб. - 1965. - Т. 68(110), № 3. - С. 313 - 327.

6. Кагаmata, J. Sur la sommation des series de Fourier des functions continue / J. Kaгamata, M. Tomic // Publ. Inst. Math. Acad. Serbe scL. - 1955. - No. 8. - P. 123-138.

7. Rozenblum, M. Summability of Fourier series in $L^{p}(d \mu) /$ M. Rozenblum// Trans. Amer. Math. Soc. -1962 - - Vol. 105. - P. 32-42.

8. Muckenhoupt, B. Weighted Norm Inequalities for the Hardy Maximal Function / B. Muckenhoupt // Trans. Amer. Math. Soc. - 1972. - Vol.165. - P. 207 - 226.

9. Зигмунд, А. Тригонометрические ряды : пер. с англ. : в 2 т. / А. Зигмунд. М. : Мир, 1965. -2 т.

10. Кук, Р. Бесконечные матрицы и пространства последовательностей : монография / Р. Кук. - М. : ГИФМЛ, 1960. - 471 с.

11. Nakhman, A. D. Exponential Methods of Summation of the Fourier Series / A. D. Nakhman, B. P. Osilenker // Вестн. Тамб. гос. техн. ун-та. -2014. - T. 20, № 1. C. $101-109$.

\section{Regelmäßige halbununterbrochene Methoden der Summierung der Fourierreihen}

Zusammenfassung: Die halbununterbrochenen Methoden der Summierung verwendend, wird die Klasse der mittleren Fourierreihen gebaut, die fast überall, sowie in den Metriken der Waageräume und des Raums $C$ der ununterbrochenen periodischen Funktionen übereinstimmen. Es ist bestimmt, dass eine ausreichende Bedingung solcher Konvergenz und der Gerechtigkeit - der Waageeinschätzungen der entsprechenden maximalen Operatoren die verallgemeinerte Bedingung von B. Nagy ist. Die Ergebnisse sind zu der Forschung des Verhaltens der exponentialen mittleren Fourierreihen angelegt und schließen die Fälle der klassischen Mittlwerten von Cesaro, Riesz, and AbelPoisson ein.

\section{Méthodes régulières semi-continues de la sommation des séries de Fourier}

Résumé: En utilisant les méthodes régulières semi-continues de la sommation, on construit une classe des séries moyennes de Fourier se convergeant presque partout, ainsi que dans les mesures des espaces de poids $L_{v}^{p}\left(v \in A_{p}, p \geq 1\right)$ et de l'espace $C$ des fonctions périodiques continues. Est donstaté que la condition suffisante pour une telle convergence et la justice de $L_{v}^{p}$ de poids des évaluations des opérateurs maximums correspondants est la condition généralisante $\mathrm{B}$. Nadia. Les résultats sont appliqués à l'étude du comportement des séries moyennes de Fourier exponentielles moyennes et comprennent les cas des moyennes classiques de Cesaro, Riesz et Abel-Poisson.

Авторы: Нахман Александр Давидович - кандидат физико-математических наук, доцент кафедры «Техническая механика и детали машин», ФГБОУ ВО «ТГТУ», г. Тамбов, Россия; Осиленкер Борис Петрович - доктор физико-математических наук, профессор кафедры «Прикладная математика», ФГБОУ ВО «Национальный исследовательский Московский государственный строительный университет», г. Москва, Россия.

Рецензент: Куликов Геннадий Михайлович - доктор физико-математических наук, профессор, заведующий научно-исследовательской лабораторией «Механика интеллектуальных материалов и конструкций», ФГБОУ ВО «ТГТУ», г. Тамбов, Россия. 